\title{
Joe Deville, Michael Guggenheim, \& Zuzana Hrdličková (eds) (forthcoming, 2016) Practicing Comparison: Logics, Relations, Collaborations. Manchester: Mattering Press. 199 pages. ISBN 978-0-9931449-0-5.
}

\author{
Steven D. Brown \\ sb343@leicester.ac.uk
}

It seems almost obligatory to start with a comparison. On the one side, the great sociologist Niklas Luhmann pulling cards from his filing cabinet, constructing texts which he claims are practically authored by the comparative process itself. On the other, the renowned anthropologist Eduardo Viveiros de Castro (2004: 14) provocatively asserting that 'It is only worth comparing the incommensurable, comparing the commensurable is a task for accountants, not anthropologists' (see Stockelova's chapter for more on this). It is the space in-between these two vivid images that this collection seeks to occupy.

Comparison, or perhaps simply the thought of comparison, seems to do strange things to those who engage in it (which as many of the contributors argue here, is practically all working social scientists at some point or another). If Luhmann can discern the logic of any given aspect of the modern world through rummaging in his card sorter, and Viveiros de Castro can argue for comparing practically anything with anything (just so long as the comparison is not initially obvious), then it seems that a strong orientation to comparison is a matter of academic reputation. Knowing what kind of 'comparator' one is, or the kinds of comparative practices one wittingly or unwittingly participates in, is described in this volume as a critical matter. In fact, as Krause argues, this is a more important matter than aligning oneself with any particular body of theory, since to think comparison properly is to think it outside of the constraints of theory.

A fun thought experiment to play with many edited collections is to imagine the authors sat together around a seminar table. Who will be the naughty one, deliberately provoking the others? Who will intervene in a calm measured tone, urging the need for synthesis? Who will sit there quietly furious, determined to have done with the conversation? Fortunately this is unnecessary with this collection. The authors are all, more or less, in agreement that a) comparison has a deserved bad reputation and we have spent some time running away from it as a practice, and b) that this has only rendered the process of comparison opaque and we must creatively rework how comparison is enacted. This is addressed by all of the authors without any grandstanding or theoretical hi-jinkery. The overwhelming sense is of sleeves rolled up and hard work being done systematically.

The stakes of rejecting comparison are made very clear by Rijke et al. In their discussion of studies around ranking and metrics in Dutch Healthcare and Biomedical Research, they demonstrate the performativity of measurement by seeking to view one disciplinary practice through the lens of the other. In doing so, they deliberately enact that well-known academic problem of being judged by the standards of another (i.e. social science evaluated by the income-gener- 
ating metrics of engineering) in order to expose unexpected connections and contrasts. One tension they reveal is between the 'technologies' of comparison, when they describe how, after studying the way scientists and medics struggle to redefine one another's metrics, the research team retreats to a coffee shop to do their own comparative work. But this is rapidly counterbalanced when the authors note their participation in highlevel benchmarking and performance management activities. Science may have the numbers, but the social scientists seem to have the discursive resources to do comparison differently.

Another risk is that of being captured in large research initiatives, such as EC framework programmes, that require comparison as part of the project of constituting a common European research agenda. Three chapters are dedicated to reflections on such experiences and the difficulties of working with comparison (this will do little, I suspect, for the mood or sympathy of those readers who would only just stop short of killing to secure this kind of funding). Akrich \& Rabeharisoa offer an 'auto-ethnography' of their particular FP7 project. They describe, using material from meetings and emails, how the project team found its way through the variety of comparisons that they had implied in their initial proposal. In the end, delaying the 'theoretical moment' after rather than before the comparison proved the way forward.

Gad \& Jensen worry in a similar vein about the demand for comparison and where it comes from. They point to 'indigenous comparisons' as a means of analysis. Comparisons are a part of the field rather than simply imposed by the analyst, and they may well be embedded into technical arrangements that do a work of auto-comparison. What is particularly interesting here is the resonance with ethnomethodological concerns about 'members categories' and the place of the analyst in relation to these 'bottom up' features of (techno)sociality. As with Rijke et al., part of the message here seems to be that our discursive skills at forging comparison are themselves part of a complex comparative relation with the language games of those we study. This is demonstrated well by Meyer who, in effect, offers a form of Membership Categorisation Analysis to show how the descriptive practices of biohackers have implications for their identity work.

Although there are moments throughout the collection where there is a sense that the thematic of comparison has led to the recuperation of existing epistemic procedures, there a plenty of moments of genuine novelty. Gad \& Jensen's argument for 'lateral comparisons' is highly suggestive for the mobilisation of ethnographic description in STS. Similarly, Lutz's notion of 'comparative tinkering' is far more promising than the now standard recourse to the term 'experimentation' to describe the creative labour of reframing data through loose and partial connections. Faria beautifully illustrates how 'comparing the incomparable' (in this case different examples of colonial architecture in India) can be done thoughtfully and rigorously. Just don't try convincing historians of that.

Some of these threads are drawn together in Deville et al.'s chapter, which places the collectivity of analysis at its centre. They describe their research team as having become a 'comparator' - a device that produces auto-comparisons when 'fed' with relevant data. In doing so they re-introduce an important sense that our analytic skill does not come from comparing anything with anything, but rather from the situated act of being exposed to particular opportunities where we work in concert with one another to develop and exploit intellectual and practical connections. This takes us back to Akrich \& Rabeharisoa's notion that doing research places us into the trap of comparison, but also delivers us the access and data to find a way out.

Isabelle Stengers (2011) haunts much of this collection, particularly in Robinson's concluding chapter, which ends up effectively saying that the reader should take a look at Stengers' 'Comparison as a matter of concern' piece. I very much doubt that many readers of this volume will not already be familiar with that work. But what they will find here is a fine collection of essays by researchers who engage with comparison as a live analytic and empirical concern, and who have the authorial skills to convince that this an essential debate with profound implications. 


\section{References}

Viveiros de Castro E (2004) Perspectival Anthropology and the Method of Controlled Equivocation. Tipití: Journal of the Society for the Anthropology of Lowland South America 2(1): Article 1.

Stengers I (2011) Comparison as a matter of concern. Common Knowledge 17(1): 48-6. 